\title{
GERIATRIC HEALTH PROBLEMS AND HEALTH CARE SEEKING PRACTICE AMONG ELDERLY PEOPLE ATTENDING ONE SELECTED GERIATRIC HOSPITAL
}

\author{
MAHJABEEN SULTANA BEGUM
}

Assistant Professor, Department of Community Medicine, Zainul Haque Sikder Women's Medical College, Dhaka

\begin{abstract}
A vast majority of the elderly Bangladeshi people is suffering from various health problems, however, health care services are insufficient to cope with the problem. This study tried to find out about the geriatric health problems and health care seeking practice attending a selected hospital in Dhaka city. The information collected may help provide adequate guideline to help the elderly to overcome old age health problems.

This was a cross sectional study and included 107 respondents aged 60 years and above. The study was carried out during March June, 2001, at Prabin Hitayishi Hospital, Bangladesh Association of Aged and Institute of Geriatric Medicine (BAAIGM), Agargaon, Sher e Bangla Nagar, Dhaka.

Out of 107 respondents, $46.7 \%$ were aged 65 years or above, $67.3 \%$ were married, 14\% were living with spouse, $23.4 \%$ were employed, $46.7 \%$ had self income and $19.6 \%$ were living in families with 9 or more members. Knowledge about old age diseases were limited to diabetes (57.9\%), high blood pressure (53.3\%), heart diseases (50.4\%), respiratory diseases (31.8\%), and orthopaedic diseases (3.7\%), and 41.1\% had no knowledge. Regarding health care knowledge, 67.3\% had knowledge about self health care, $29.9 \%$ were on regular check up and $78.5 \%$ attended hospital. Morbidity pattern showed that most of the respondents (23.4\%) had orthopaedic problems, followed by eye (21.5\%), dental (12.4\%), ENT (12.1\%), respiratory (9.3\%), gastrointestinal (7.5\%), diabetes (2.8\%) and neurological (2.8\%). Six respondents had multiple diseases. Specific diseases in orthopaedic group $(n=25)$ were spondylitis (60\%), rheumatoid arthritis (20\%) and osteoporosis, osteomyelitis, backpain and frozen shoulder (20\%); in eye disease group $(n=23)$ were refractory error (34.8\%), conjunctivitis (30.4\%), cataract (17.4\%) and presbyopia (17.4\%); in dental disease group (n=14) were loose teeth (78.5\%) and dental caries (21.4\%); in ENT disease group ( $n=14)$ were CSOM (57\%), tinnitus (35\%) and vertigo and hearing loss (7.1\%); in cardiovascular group ( $n=13)$ were hypertension (84\%) and old myocardial infarction and ischaemic heart disease (15.3\%); and in respiratory disease group $(n=10)$ were pharyngitis sinusitis (60\%), bronchial asthma (20\%) and bronchitis (20\%). Health care seeking pattern was orthopaedic $40 \%(n=25)$, eye 13\% $(n=23)$, dental 14.3\% ( $n=14)$, ENT 21.4\% ( $n=14)$, cardiovascular 38.5\% $(n=13)$, respiratory 40\% $(n=10)$, gastrointestinal 25\% ( $n=8)$, endocrine 66.7\% (n=3) and neurological $33.3(n=3)$.
\end{abstract}

Most of the elderly did not seek health care from hospital or clinic.

Key words: Health care, Elderly

(Bangladesh J Physiol Pharmacol 2007; 23(1\&2) : 20-24)

\section{INTRODUCTION}

Individuals of 60 years and above age are prone to develop certain diseases and ailments which are uncommon in younger age groups. The disorders are of two types: age dependent, which occurs as a direct consequence of physiological senescence with least

Address of Correspondence: Dr. Mahjabeen Sultana Begum, Assistant Professor, Department of Community Medicine, Zainul Haque Sikder Women's Medical College and Hospital, Monika Estate, Rayer Bazar, Dhaka. possibility of treatment or control, and age related, which are more prevalent in the advanced life which can be prevented. ${ }^{1}$ However, in order to overcome old age health problems, not everyone has access to proper health care facilities due to ignorance, lack of family support, easy accessibility to health care facilities, financial constraints, etc.

In comparison to urban areas, access to health care services is limited in rural areas. ${ }^{2}$ Decrease in fertility rate and improvement in life expectancy have led to rapid 
increases in number of older people in Bangladesh with 80,000 new elderly added every year to over 60 years age group, ${ }^{2}$ which represents approximately 7.3 million people. $^{3}$

In Bangladesh, majority of the elderly people are suffering from some basic problems, such as lack of sufficient income, employment opportunities, malnutrition, chronic diseases, absence of proper health care facilities and lack of adequate family support. Furthermore, problems of elderly people in our country vary according to their socioeconomic status and residence.

This study was carried out to find out the health care seeking practice among the elderly attending a selected hospital in Dhaka city. The information collected may help provide adequate guideline to help the elderly to overcome old age health problems.

\section{MATERIALS AND METHODS}

This cross sectional study was carried out during March June, 2001, Prabin Hitayishi Hospital, Bangladesh Associated of Aged and Institute of Geriatric Medicine (BAAIGM), Agargaon, Sher e Bangla Nagar, and included 107 respondents aged 60 years and above, and irrespective of sex. Prior permission was obtained from concerned authorities to carry out the study.

No set sampling technique was followed for selection of the respondents. Data were collected from all the elderly who attended the outpatient department for health care during 7 days, excluding holidays.

Predesigned and pretested questionnaire was used to collect data from the study population. ABengali version of the questionnaire with both open and close ended questions were prepared to collect data from the respondents. Relevant information was collected by direct question and answer given by the respondents and from hospital record books.

Collected data was compiled and appropriate statistical analyses were done using computerbased software, Statistical Package for Social Science (SPSS).

\section{RESULTS}

Out of 107 respondents $46.7 \%$ were aged 65 years or above, $67.3 \%$ were married $14 \%$ were living with spouse, $23.4 \%$ were employed, $46.7 \%$ had self income and $19.6 \%$ were living in families with 9 or more members (Table I).

Table II shows that out of 107 respondents 63 (58.9\%) were aware of type of old age diseases, and most common diseases were diabetes (57.9\%), high blood pressure (53.3\%), heart diseases (50.4\%) and respiratory diseases (31.8\%). In some cases, the response was multiple.
Table I

Sociodemographic characteristics of the respondents

\begin{tabular}{|c|c|c|}
\hline Parameters & Number & Percentage \\
\hline \multicolumn{3}{|l|}{ Age (years) } \\
\hline$<65$ & 57 & 53.3 \\
\hline$>65$ & 50 & 46.7 \\
\hline \multicolumn{3}{|l|}{ Marital status } \\
\hline Married & 72 & 67.3 \\
\hline Others & 35 & 32.5 \\
\hline \multicolumn{3}{|l|}{ Living status } \\
\hline With spouse & 15 & 14.0 \\
\hline With others & 92 & 86.0 \\
\hline \multicolumn{3}{|l|}{ Occupation } \\
\hline Engaged & 25 & 23.4 \\
\hline Housewife & 38 & 35.5 \\
\hline Others & 44 & 41.1 \\
\hline \multicolumn{3}{|l|}{ Self income } \\
\hline Yes & 50 & 46.7 \\
\hline No & 57 & 53.3 \\
\hline \multicolumn{3}{|l|}{ Family members } \\
\hline 24 & 16 & 15.0 \\
\hline 56 & 30 & 28.0 \\
\hline 78 & 40 & 37.4 \\
\hline$>9$ & 21 & 19.6 \\
\hline
\end{tabular}

Table II

Knowledge about old age diseases $(n=107)$

\begin{tabular}{lcc}
\hline Diseases & Number & Percentage \\
\hline Diabetes & 62 & 57.9 \\
High blood pressure & 57 & 53.3 \\
Heart disease & 54 & 50.4 \\
Respiratory diseases & 34 & 31.8 \\
Orthopaedic diseases & 4 & 3.7 \\
Do not know & 44 & 41.1 \\
\hline
\end{tabular}

Regarding knowledge about self health care, $67.3 \%$ respondents had knowledge about self health care, $29.9 \%$ were on regular check up and $78.5 \%$ attended hospital in spite of referral by non medical personnel, such as friends, acquaintances or family members (Table III). 
Table III

Health care pattern $(n=107)$

\begin{tabular}{lcc}
\hline Parameters & Number & Percentage \\
\hline Knowledge about self health care & & \\
Yes & 72 & 67.3 \\
No & 35 & 32.7 \\
Regular health check up & & \\
Yes & 32 & 29.9 \\
No & 75 & 70.1 \\
Referred to hospital by & & \\
Medical personnel & 23 & 21.5 \\
Others & 84 & 78.5 \\
\hline
\end{tabular}

Pattern of morbidity prevailing among the respondents shows that most common were orthopaedic (234.\%), eye (21.5\%), dental (12.4\%), ENT (12.4\%), cardiovascular (12.4\%), etc. (Table IV).

Table IV

Pattern of morbidity $(n=107)$

\begin{tabular}{lcc}
\hline Diseases & Number & Percentage \\
\hline Orthopaedic & 25 & 23.4 \\
Eye & 23 & 21.5 \\
Dental & 14 & 12.4 \\
ENT & 14 & 12.4 \\
Cardiovascular & 13 & 12.1 \\
Respiratory & 10 & 9.3 \\
Gastrointestinal & 8 & 7.5 \\
Endocrine & 3 & 2.8 \\
Neurological problems & 3 & 2.8 \\
\hline
\end{tabular}

Specific disease pattern shows that spondylitis was most common problem (60\%) in orthopaedic category, refractory error $(34.8 \%)$ in eye category, loose teeth $(78.5 \%)$ in dental category, CSOM (57\%) in ENT category, hypertension (84\%) in cardiovascular category and pharyngitis sinusitis (60\%) in respiratory category (Table V).

Table VI shows morbidity pattern of the elderly according to frequency of suffering and health care seeking pattern. Six respondents had multiple diseases. Out of 3 respondents suffering from diabetes (endocrine disease), $2(66.7 \%)$ sought health care, followed by 10 (40\%) for orthopaedic problems out of 25, 4 (40\%) for respiratory problems out of 10, 5 (38.5\%) for cardiovascular problems out of 13, 1 (33.3\%) for neurological problems out of 3, 2 (25\%) for gastrointestinal problems out of 8,2 for (14.3\%) for dental problems out of 14 and 3 (13\%) for eye problems out of 23.
Table V

Specific disease pattern of the respondents

\begin{tabular}{|c|c|c|}
\hline Disease pattern & Number & Percentage \\
\hline \multicolumn{3}{|l|}{ Orthopaedic (n=25) } \\
\hline Spondylitis & 15 & 60.0 \\
\hline Rheumatoid arthritis & 5 & 20.0 \\
\hline $\begin{array}{l}\text { Osteoporosis, osteomyelitis, } \\
\text { backpain and frozen shoulder } \\
\text { Eye }(n=23)\end{array}$ & 5 & 20.0 \\
\hline Refractory error & 8 & 34.8 \\
\hline Conjunctivitis & 7 & 30.4 \\
\hline Cataract & 4 & 17.4 \\
\hline Presbyopia & 4 & 17.4 \\
\hline \multicolumn{3}{|l|}{ Dental $(n=14)$} \\
\hline Loose teeth & 11 & 78.5 \\
\hline Dental caries & 3 & 21.4 \\
\hline \multicolumn{3}{|l|}{ ENT $(n=14)$} \\
\hline CSOM & 8 & 57.0 \\
\hline Tinnitus and vertigo & 5 & 35.0 \\
\hline Hearing loss & 1 & 7.1 \\
\hline \multicolumn{3}{|l|}{ Cardiovascular (n=13) } \\
\hline Hypertension & 11 & 84.0 \\
\hline \multicolumn{3}{|l|}{$\begin{array}{l}\text { Old myocardial infarction } \\
\text { and ischaemic }\end{array}$} \\
\hline heart disease & 2 & 15.3 \\
\hline \multicolumn{3}{|l|}{ Respiratory $(n=10)$} \\
\hline Pharyngitis sinusitis & 6 & 60.0 \\
\hline Bronchial asthma & 2 & 20.0 \\
\hline Bronchitis & 2 & 20.0 \\
\hline
\end{tabular}

Table VI

Disease and health check up pattern of the respondents

\begin{tabular}{lccc}
\hline \multirow{2}{*}{ Disease } & \multicolumn{3}{c}{ Regular health check up } \\
& $\begin{array}{c}\text { Yes } \\
\text { Number } \\
(\%)\end{array}$ & $\begin{array}{c}\text { Number } \\
(\%)\end{array}$ & $\begin{array}{c}\text { Total } \\
\text { Number } \\
(\%)\end{array}$ \\
\hline Orthopaedic & $10(40.0)$ & $15(60.0)$ & $25(23.4)$ \\
Eye & $3(13.0)$ & $20(87.0)$ & $23(21.5)$ \\
Dental & $2(14.3)$ & $12(85.7)$ & $14(12.4)$ \\
ENT & $3(21.4)$ & $11(78.6)$ & $14(12.4)$ \\
Cardiovascular & $5(38.5)$ & $8(61.5)$ & $13(12.1)$ \\
Respiratory & $4(40.0)$ & $6(60.0)$ & $10(9.3)$ \\
Gastrointestinal & $2(25.0)$ & $6(75.0)$ & $8(7.5)$ \\
Endocrine & $2(66.7)$ & $1(33.3)$ & $3(2.8)$ \\
Neurological & $1(33.3)$ & $2(66.7)$ & $3(2.8)$ \\
\hline Total & $32(28.3)$ & $81(71.7)$ & $113(100.0)$ \\
\hline
\end{tabular}




\section{DISCUSSION}

From this small cross sectional study limited to one hospital of Dhaka city, it was found that $53.3 \%$ respondents were aged less than 65 years and $46.7 \%$ aged 65 or above, which is similar to findings by Azhar et al. ${ }^{4}$ In a study by Bhatla et al., $53.8 \%$ belonged to age group below 65 years and $46.2 \%$ were aged 65 or more. ${ }^{5}$ With regard to marital status, $67.3 \%$ were married and $32.5 \%$ were either widow/widower or divorced. This finding is similar to the finding by Bertil et al. ${ }^{9}$

Although in our study $67.3 \%$ were married, but only $14 \%$ were living with their spouse, lacking emotional and physical support. The rest $86 \%$ respondents were living with their children who cannot provide required attention to their parents because of their own engagements, like income generating and full attention to their spouse and children.

Since all the respondents belonged to old age group, only $23.4 \%$ were engaged in occupations like job, business or farming, 35.5\% were housewives and 41.1\% were either retired or unemployed. However $56.7 \%$ respondents had their own income either from their own income generating engagements or savings.

Most of the respondents to family size 78 members $(37.4 \%)$, which is similar to the findings by Jabeen. ${ }^{7}$

Out of 107 respondents 63 (58.9\%) were aware of type of old age diseases, most common being diabetes, high blood pressure, heart diseases and respiratory diseases. Jabeen in her study also found similar results. ${ }^{7}$

In our study, maximum number of respondents were health conscious (67.3\%) and as such they were engaged in physical activities, such as social work, walking, sports, exercise, etc. Jabeen's finding is also similar to the finding of the present study. ${ }^{7}$

Status of regular health check up showed that only $29.9 \%$ respondents could avail the opportunity. The rest $70.1 \%$ lacked regular health check up may be due to time or financial constraints, dearth of health care facilities in the locality, or ignorance or lack of family support. However, referral to hospital was mostly encouraged by spouse or by family members (78.5\%).

Health care seeking practice according disease pattern showed that $25(23.4 \%)$ respondents were suffering from orthopaedic problems $(10,40 \%$ on regular health check up), 23 (21.5\%) from eye problems (3, 13\% on regular health check up), 14 (12.4\%) from dental problems (2, $14.3 \%$ on regular health check up), 13 (12.1\%) from ENT problems $(3,21.4 \%)$ on regular health check up), 13 (12.1\%) from cardiovascular problems (5, $38.5 \%$ on regular health check up), 10 (9.3\%) from respiratory problems $(4,40 \%)$ on regular health check up), 8 (7.5\%) from gastrointestinal problems (2, $25 \%$ on regular health check up), 3 (2.8\%) from diabetes $(2,66.7 \%$ were on regular health check up and $3(2.8 \%)$ from neurological problems $(1,33.3 \%$ on regular health check up).

Orthopaedic problems (23.4\%) included diseases of bones and connective tissues, such as spondylitis, osteomyelitis, osteoporosis, low back pain, frozen shoulder, etc. This finding is consistent with the findings of Ibrahim et al. ${ }^{8}$

The most common vision problems (21.5\%) were refractory errors, conjunctivitis, presbyopia and cataract. Shak and Prabhakar also observed similar prevalence. ${ }^{9}$

Common dental problems (12.4\%) were loose teeth and caries. Studies by Ibrahim et al. and Shak and Prabhakar showed similar results. ${ }^{8,9}$

In our study, ENT problems (12.4\%) were CSOM, tinnitus and vertigo, which is consistent with other studies. 8,9

Cardiovascular diseases (12.1\%) were hypertension, old myocardial infarction and ischaemic heart disease. In one study $34.7 \%$ respondents were suffering from cardiovascular diseases. ${ }^{3}$

In our study, respiratory diseases (9.3\%) found were pharyngitis. sinusitis, bronchial asthma and bronchitis, which is consistent with other similar studies. ${ }^{8,9}$

Gastrointestinal disease (7.5\%), all being peptic ulcers, agreed with the study by Linda and Trudy, ${ }^{10}$ but not with studies by Ibrahim et al. ${ }^{8}$ and Shak and Prabhakar. $^{9}$ The inconsistency may be due to the fact that respondents of our study and that of Linda and Trudy were most educated which was not the case in studies by Ibrahim et al. and Shak and Prabhakar.

Prevalence of diabetes (2.8\%) and neurological (2.8\%) among our respondents were less as there and excellent treatment facilities in Dhaka city for these two diseases.

\section{CONCLUSION}

Health care seeking practice was very low among the aged respondents. This may be attributed to ignorance or poverty or social negligence.

\section{REFERENCES}

1. Ali MY. Textbook of community medicine and public health. 3rd ed. Dhaka: RKH Publishers; 1999.

2. ESCAP Population Data Sheet; 1999.

3. Samad MA, Samad A. Implication of Asian population future and elderly. BJG 1999; 12941. 
4. Azhar M, Chowdhury JM, Ahsan N, Rafiquddin MAK. Geriatric disease and geriatric problems amongst medical indoor patients. Teachers Association Journal (TAJ) 1994; 7:47 9 .

5. Bhatla PC, et al. Care of the elderly. A round table discussion, New Delhi, December 1986.

6. Bertil SH, Syen O, Lars J, Sven EL. Social network an social support influence mortalities in elderly man. Am J Epidemiol 1999; 130:100 30.
7. Jabeen S. Self health care among the senior citizen attending BAAIGM, Dhaka, Bangladesh; 1998.

8. Ibrahim M, Rahman MA, et al. A survey on health and socioeconomic problems of the aged in Bangladesh. Dhaka: BAAIGM; 1998.

9. Shak B, Prabhakar AK. Chronic morbidity profile among elderly. Indian J Med Res 1997; 106:265 72.

10. Linda PF, Trudy LB. Morbidity as a focus of preventive health care in the elderly. Ep Rev John Hopkins University 1988; 10:48 63. 